http://jmscr.igmpublication.org/home/

ISSN (e)-2347-176x ISSN (p) 2455-0450

crossref DOI: https://dx.doi.org/10.18535/jmscr/v7i10.113

Journal Of Medical Science And Clinical Research

\title{
Acute Myocardial Infarction Following an Indian red Scorpion Sting
}

\author{
Authors
}

\section{Dr Gokul Bharathi.K ${ }^{1}$, Dr R.Aswinth ${ }^{2}$, Prof. Dr S.Sudharsan ${ }^{3}$}

${ }^{1}$ Post Graduate, Department of General Medicine, Rajah Muthiah Medical College \& Hospital,

Annamalai University, Chidambaram, India - 608002

${ }^{2}$ Assistant Professor, Department of General Medicine, Rajah Muthiah Medical College \& Hospital,

Annamalai University, Chidambaram, India - 608002

${ }^{3}$ Professor, Department of General Medicine, Rajah Muthiah Medical College \& Hospital,

Annamalai University, Chidambaram, India - 608002

Abstract
Acute myocardial infarction following scorpion sting has been reported in few cases. A 55 years old male
developed ST segment elevation following an Indian red scorpion sting and angiogram revealed significant
stenosis of right coronary artery. The possible mechanism in this case could be atherosclerotic plaque
rupture following sympathetic over activity owing to scorpion bite.

\section{Background}

Scorpion envenomaion is a major health problem in Asian and South East Asian countries. Sometimes it manifests as significant life threatening, acute time limiting cardiovascular emergency. The Indian red scorpion Mesobthus tumulus is the most lethal among all the poisonous species of scorpion. ${ }^{1}$ Cardiovascular manifestations are more common following stings by Indian red scorpion (Myocardial Infarction, Acute Pulmonary edema, Cardiogenic shock and even death. Myocardial infarction with normal coronary angiogram following scorpion sting was reported in several cases. But in this case myocardial infarction following scorpion sting had significant stenosis of coronary arteries. ${ }^{4}$

\section{Case Presentation}

A 55 years old male presented to the casualty with pain in the left little finger one hour after being stung by a Indian red scorpion. Patient was not a known case of Diabetes/ Hypertension/ Bronchial
Asthma/ Epilepsy/ Coronary artery disease. There was no family history of Coronary artery disease. On examination his BP -170/90mmhg, HR 120/min regular and RR-18/min, ECG showed normal sinus rhythm with no specific ST/T changes. He was treated with alpha blocker prazosin. Patient was admitted and kept on observation.

Two hours later patient developed chest discomfort and tightness, sweating, palpitation. His repeat ECG showed ST elevation in II, III, aVF. Serum CKMB was 110units/litter. Patient was treated with antiplatelets, Nitroglycerine. On the second day of admission his 2D Echocardiogram showed hypokinesia of inferior wall and ejection fraction 65\%.Coronary angiogram done on the third day revealed significant stenosis of right coronary artery. $\mathrm{He}$ was treated with medications including dual antipltelets, beta blockers, statins, sorbitrate and ACE inhibitors. His admission course was smooth and was discharged after 5 days. 


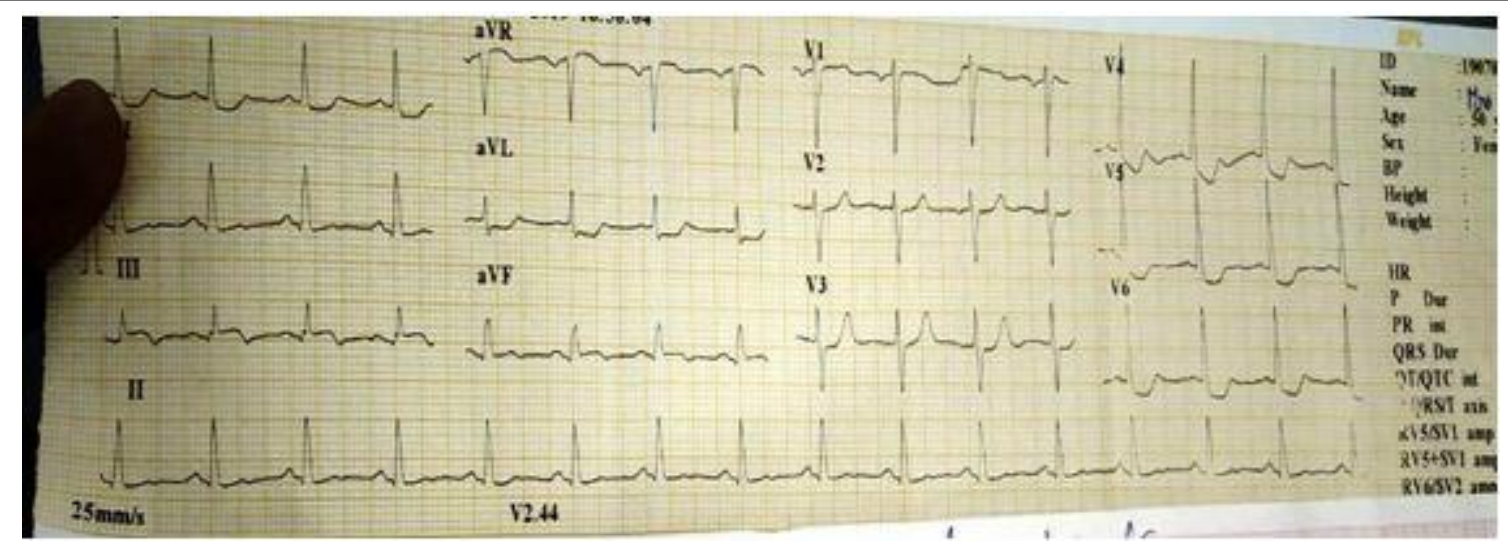

\section{Discussion}

Scorpion venom is a water soluble antigenic complex mixture of neurotoxin, cardiotoxin, nephrotoxin, hemolysin, phosphodiesterase, phospholipase, hyaluronidase, histamine and other chemicals. The venom can cause myocardial damage by several pathogenic mechanism. ${ }^{5}$

First, myocardial ischemia caused by coronary spasm because of the release of vasoactive, inflammatory and thrombogenic peptides and amine constituents (histamine, bradykinin, leukotriene, serotonin) which act on the coronary vessels and induce coronary spasm and augment platelet aggregation as well as thrombosis. Second, direct cardiotoxic effect of the venom can cause toxic myocarditis. $^{2}$

In our case acute ST segment elevation is due to significant coronary artery disease which was evident following scorpion sting. The underlying mechanism for ST segment elevation in our case could be atherslerotic plaque rupture following sympathetic activity due to scorpion sting. ${ }^{3}$ This is similar to type 2 kounis syndrome which occour in people with underlying asymptomatic coronary artery disease where an allergic reaction leads to coronary artery spasm or plaque rupture.

So in every case with features of acute coronary syndrome following scorpion sting thorough cardiological examination and coronary angiogram is important to rule out any underlying coronary artery disease.

\section{Conclusion}

Painful but relatively harmless scorpion stings need to be differentiated from potentially lethal envenomation that are produced by 30 out of 1000 known species that can cause more than 5000 deaths worldwide each year. Cardiological examination and coronary angiogram is mandatory in all potentially lethal envenomation produced by scorpion stings.

\section{Reference}

1. API textbook of medicine $19^{\text {th }}$ edition.

2. Harrsisons principles of internal medicine $20^{\text {th }}$ edition.

3. Soumya patra, Satish kk, Vivek singla, Ravindranath KS. Acute myocardial infarction following scorpion sting in a case with obstructive coronary artery disease. BMJ Case Rep. 2013 May 27; 2013. pii: bcr2013009865. Doi: 10.1136/bcr-2013-009865.

4. PK Ramalingam et al. transient ST segment elevation following Indian red scorpion sting with non-occlusive right coronary artery disease, Japi Vol:64, May: 2016.

5. VV Pillay text book of forensic medicine and toxicology $19^{\text {th }}$ edition. 